\title{
Idosos em situação de rua ou vulnerabilidade social: facilidades e dificuldades no uso de ferramentas computacionais
}

\author{
Elderlies in street situation or social vulnerability: facilities and difficulties in the use of computational tools \\ Ancianos en situación de calle o vulnerabilidad social: facilidades y dificultades \\ en el uso de herramientas computacionales
}

\section{Marcos Antonio da Eira Frias', Heloisa Helena Ciqueto Peres", Valclei Aparecida Gandolpho Pereira', Maria Célia de Negreiros', Wana Yeda Paranhos', Maria Madalena Januário Leite"}

'Universidade Cidade de São Paulo, Curso de Enfermagem. São Paulo-SP, Brasil.

"Universidade de São Paulo, Escola de Enfermagem. São Paulo-SP, Brasil.

\author{
Submissão: 14-12-2012 Aprovação: 08-07-2014
}

\section{RESUMO}

Este estudo teve por objetivo identificar as facilidades e dificuldades encontradas por idosos em situação de rua ou vulnerabilidade social, no uso do computador ou internet. É uma pesquisa qualitativa do tipo exploratório, de que participaram cinco idosos assistidos em uma Organização não Governamental situada na cidade de São Paulo. Os discursos foram analisados pela Técnica de Análise de Conteúdo e evidenciaram como facilidades, dentre outras, esclarecer dúvidas com os monitores, o estímulo para novas descobertas aliada a proatividade e curiosidade, desenvolvimento de novas habilidades. As dificuldades estavam relacionadas a questões físicas ou cognitivas, à falta de instrutor e de conhecimento para interagir com a máquina. Os estudos voltados para a população idosa em situação de rua ou vulnerabilidade social podem contribuir com evidências que direcionem a formulação de políticas públicas voltadas para essa parcela da população.

Descritores: Idoso; Vulnerabilidade Social; Tecnologia da Informação.

\begin{abstract}
This study aimed to identify the advantages and difficulties encountered by older people living on the streets or social vulnerability, to use the computer or internet. It is an exploratory qualitative research, in which five elderlies, attended on a non-governmental organization located in the city of São Paulo, have participated. The discourses were analyzed by content analysis technique and showed, as facilities, among others, to clarify doubts with the monitors, the stimulus for new discoveries coupled with proactivity and curiosity, and develop new skills. The mentioned difficulties were related to physical or cognitive issues, lack of instructor, and lack of knowledge to interact with the machine. The studies focusing on the elderly population living on the streets or in social vulnerability may contribute with evidence to guide the formulation of public policies to this population.
\end{abstract}

Key words: Aged; Social Vulnerability; Information Technology.

\section{RESUMEN}

Este estudio tuvo como objetivo identificar las facilidades y dificultades encontradas por las personas mayores en situación de calle o vulnerabilidad social, en el uso de computadores o internet. Se trata de una investigación cualitativa exploratoria, a la que asistieron cinco personas mayores, asistidos en una Organización no Gubernamental ubicada en la ciudad de São Paulo. Los discursos fueron analizados por la técnica de análisis de contenido y evidencian como facilidades, entre otras cosas, aclarar dudas con los monitores, el estímulo para nuevas descubiertas asociadas a la pro actividad y curiosidad y al desarrollo de nuevas habilidades. Las dificultades se relacionaban con cuestiones físicas o cognitivas, a la falta de instructor y falta de conocimiento para interactuar con la máquina. Los estudios direccionados para la población anciana en situación de calle o vulnerabilidad social pueden contribuir con evidencias que direccionen la formulación de políticas públicas en beneficio de esa parcela de la población.

Palabras clave: Anciano; Vulnerabilidad Social; Tecnología de la Información.

$$
\text { AUTOR CORRESPONDENTE Marcos Antonio da Eira Frias E-mail: mfrias.enf@gmail.com }
$$




\section{INTRODUÇÃO}

As circunstâncias que levam um indivíduo à situação de rua são múltiplas, dentre as quais são prevalentes o desamparo, os desafetos familiares, as enfermidades, a perda de atividade laboral. A maneira como os moradores de rua sobrevivem, também são diferentes, e se configuram como trabalhos diversificados e precários. O único fator comum a todos, e que os unifica em um mesmo grupo social é a situação de rua que os expõe ao perigo e a condição sub-humana em que vivem ${ }^{(1)}$.

A sucessão dos dias na rua faz com que o idoso vivencie um processo progressivo de perdas que interferem expressivamente em questões ligadas à autoestima, autonomia, independência, saúde mental e qualidade de vida, por ter que depender de instituições assistenciais para realizar sua higiene pessoal, conseguir o mínimo necessário de alimentos e, consequentemente, a manutenção da saúde ${ }^{(2)}$.

Dentro dessa perspectiva de intervenção, as organizações não governamentais e as instituições de assistência social, desempenham um papel fundamental na tentativa de tirar o idoso da situação de rua ou vulnerabilidade social e reinseri-lo na sociedade, devolvendo assim sua dignidade e autoestima.

A vulnerabilidade e desigualdade social no Brasil são realidades prementes, pois existe uma carência de serviços essenciais, relacionados à saúde e assistência social, voltados para os idosos. Nessa perspectiva, percebe-se que o desenvolvimento de políticas públicas com vistas ao incremento do envelhecimento ativo e da qualidade de vida dos idosos ainda é incipiente, fato que leva à necessidade de empreendimentos por parte das organizações não governamentais, dos profissionais das mais diversas áreas e da comunidade ${ }^{(3)}$.

Fugir do assistencialismo e promover a reintegração da população de rua na sociedade, objetivando assim a autonomia e independência social, implica em valorização do ser humano, melhoria da qualidade de vida, resgate da dignidade e da autoestima. Para que isso aconteça de forma efetiva, é necessário realizar estudos e, a partir das evidências, desenvolver e implementar políticas públicas pautadas nessa realidade.

Existem poucos estudos desenvolvidos por enfermeiros abarcando a temática do idoso em situação de rua, sendo, portanto, necessário que se estimule a inserção desse profissional em atividades de assistência e cuidado a esses indivíduos. Essa vivência por parte dos enfermeiros exigirá um aporte teórico consistente, fazendo emergir assim, a necessidade de se desenvolver pesquisas que fundamentem a prestação de cuidados apropriados à realidade do morador de rua ${ }^{(2)}$.

Em um estudo de revisão bibliográfica ${ }^{(4)}$ cujo escopo foi identificar a produção cientifica de enfermagem relacionada à temática do idoso, os autores identificaram maior prevalência de pesquisas relacionadas às necessidades do idoso no espaço hospitalar, onde predominam as investigações com foco na assistência curativa e poucas pesquisas relacionadas à promoção da saúde e prevenção das doenças. Ficou evidente nessa revisão a necessidade de ampliar os estudos que envolvam o idoso, sua autonomia e independência do ponto de vista do processo de cuidar na Enfermagem na perspectiva da promoção da saúde e do alcance da qualidade de vida na velhice.
A falta de estudos sobre o contexto em que vivem os idosos em situação de rua e a falta de informações sobre as características sociodemográficas dessa população, como um fenômeno social, representa uma lacuna na literatura. Esse fenômeno precisa ser alvo de estudos, pois traz em seu bojo a realidade da mudança do perfil demográfico e os problemas para reinserir a população de rua na sociedade, os desajustes na estrutura econômica, a diminuição da oferta de postos de trabalho, mão de obra especializada e o desprezo da sociedade pelo homem como sujeito de direitos ${ }^{(2)}$.

O aumento da população de rua faz emergir a necessidade de estudos voltados para as condições em que vivem esses grupos, seus arquétipos socioculturais, as crenças, os costumes, forma de sobrevivência, e assim, pensar sobre as possibilidades de intervenção por parte de profissionais de diversas áreas que se ocupam dessas questões, como os educadores, os assistentes sociais e profissionais da saúde ${ }^{(3)}$. Dentre os profissionais de saúde, destacamos particularmente a atuação do enfermeiro, eixo principal para suporte do cuidado.

O enfermeiro tem um papel importante no atendimento ao idoso, principalmente nas questões gerontológicas, com a efetivação da assistência, por meio de ferramentas computacionais e o uso do computador para acompanhamento e orientação dessa população de maneira remota. Essas ferramentas permitem criar ambientes que podem ser usados no combate à exclusão social dos idosos, uma vez que possibilitam o aprendizado contínuo, a difusão e transferência de informações e conhecimentos ${ }^{(5)}$.

Diante do exposto, entendemos que desfrutar dos benefícios oferecidos pelas instituições assistências é um subterfúgio para minimizar a dura realidade vivida pelos idosos, a qual caracteriza a vulnerabilidade da rua. Essa realidade vivida por muitos idosos carece de investigação e intervenção por parte dos enfermeiros. Assim, consideramos relevante identificar as facilidades e dificuldades encontradas por idosos em situação de rua ou vulnerabilidade social, no uso do computador ou internet.

\section{METODOLOGIA}

Trata-se de um estudo qualitativo do tipo exploratório. A pesquisa exploratória visa proporcionar maior familiaridade com o problema com vistas a torná-lo explícito ou construir hipóteses ${ }^{(6)}$. Assim sendo, pode envolver levantamento bibliográfico, entrevistas com pessoas que têm experiências práticas com o problema pesquisado, pesquisa bibliográfica ou estudo de caso $^{(6)}$.

O local de estudo foi uma Organização não Governamental (OnG) situada na região do Brás, na cidade de São Paulo-SP. A Instituição agrega várias casas, dentre elas a Unidade onde o estudo foi realizado, a qual atende idosos do sexo masculino, em situação de rua e vulnerabilidade social com o objetivo de prepará-los para a autonomia pessoal e social.

O estudo foi realizado com cinco idosos e o número de sujeitos participantes foi determinado pelos seguintes critérios de inclusão: apresentar sessenta anos ou mais; fazer uso do computador e/ou internet; estar presente no dia da coleta de dados e concordar em participar do estudo assinando o Termo de Consentimento Livre e Esclarecido. 
A coleta de dados foi realizada por meio de entrevista, a partir da pergunta norteadora "Descreva as facilidades e dificuldades encontradas quando usa o computador ou internet". Para a entrevista solicitamos a autorização para que a mesma fosse gravada, sendo posteriormente transcrita e analisada.

Os dados foram analisados utilizando-se a técnica de Análise de Conteúdo, que é um conjunto de instrumentos metodológicos que se aplicam aos "discursos" mais diversos e têm como meta a indução, a dedução e a conclusão ${ }^{(7)}$.

Para garantir o anonimato dos participantes, na apresentação dos dados, eles foram identificados com numerais sequenciais de 1 (um) a 5 (cinco). Os recortes do discurso de cada sujeito foram codificados sequencialmente a partir do número 1 (um) precedido por um ponto. E as facilidades e dificuldades foram respectivamente identificadas com as siglas Fac. e Dif. Desta maneira, os recortes dos discursos relativos às facilidades estão identificados com a sigla "Fac." e as dificuldades com a sigla "Dif.", o primeiro numeral após a sigla corresponde ao sujeito e o segundo numeral precedido pelo ponto corresponde ao recorte do discurso.

Da análise dos discursos emergiram duas categorias relacionadas às facilidades sendo elas: Categoria 1: Esclarecendo dúvidas; Categoria 2: Interagindo com a máquina e usando ferramentas digitais; Subcategoria 1: Usando programas e dispositivos; Subcategoria 2: Navegando na internet. Em relação às dificuldades emergiram três categorias nominadas: Categoria 1: Limitação física ou cognitiva; Categoria 2: Ausência de instrutor; Categoria 3: Falta de conhecimento para interagir com a máquina e usar ferramentas digitais.

O projeto deste estudo é um desmembramento do projeto principal intitulado "Tecnologia e qualidade de vida do idoso", submetido ao Comitê de Ética e Pesquisa da Universidade Cidade de São Paulo - UNICID, tendo sido aprovado em 07 de abril de 2010, Protocolo n 13496882 CAAE 0012.0.186.000-10, seguindo assim as recomendações de Resolução do Conselho Nacional de Saúde, quando se pesquisa com seres humanos.

\section{RESULTADOS}

\section{A. Facilidades no uso do computador ou internet}

Em relação às facilidades encontradas pelos idosos no uso do computador ou da internet, emergiram dos discursos duas categorias, a categoria dois apresenta duas subcategorias.

\section{Categoria 1: Esclarecendo dúvidas}

Após o agrupamento dos discursos pudemos observar que alguns deles convergiam para o mesmo ponto, a facilidade para esclarecer dúvidas em relação ao uso do computador ou acesso à internet facilitando assim a acessibilidade.

Dos discursos emergiram como facilitadores do processo de aprendizagem, o uso de manuais e a presença de monitores, colaborando e esclarecendo as dúvidas, enriquecendo o aprendizado e favorecendo a inclusão digital. Esses discursos estão apresentados a seguir.
[...] eu vou entrar e não sei, então eu primeiro pesquiso, pergunto para o técnico antes de entrar [...]. (Fac.1.1)

[...] eu não tenho muita dificuldade, e quando surge pergunto para o técnico como, por exemplo: lidar com o teclado [...]. (Fac. 1.7)

Sempre tem uma e outra pessoa que nos tira algumas duvidas, mas não é uma pessoa específica [...]. (Fac.3.5)

[...] desde que eu tenho outras dificuldades tem um livro disponível que posso consultar, no caso se tiver um instrutor eu peço uma explicação e ele vem e me explica [...]. (Fac.2.3)

\section{Categoria 2: Interagindo com a máquina e usando ferra- mentas digitais}

Nesta categoria ficou evidente que quando o idoso é estimulado ocorre um enriquecimento em sua aprendizagem, despertando-o para novas descobertas e diferentes maneiras de trabalhar com o computador e com as ferramentas digitais.

A curiosidade e a proatividade permitiram que os idosos trilhassem com mais facilidade os caminhos para a inclusão digital. A comunicação por meio das ferramentas eletrônicas foi considerada como de fácil interação e usabilidade. Esses fenômenos emergiram da fala dos idosos e estão descritos abaixo.

Não tive muitas dificuldades porque eu tinha curiosidade de aprender [...]. (Fac.3.1)

Não tenho dificuldades, hoje já domino. (Fac.3.6)

Eu aprendi a mexer no computador por conta própria, eu ia às empresas e mexia e aprendi. (Fac.4.1)

[...] eu abro e fecho com segurança, os e-mails [...]. (Fac.1.5)

[...] receber e-mail eu achei fácil [...]. (Fac.2.1)

[...] mandar um e-mail também é fácil [...]. (Fac. 2.2)

[...] sei escrever cartas [...]. (Fac. 5.1)

[...]responder pesquisas que aparecem na internet [...]. (Fac.5.3)

[...] Hoje me comunico com meus dois filhos pelo Facebook [...]. (Fac.3.2)

\section{[...] eu entro no Facebook [...]. (Fac.3.9)}

[...] agora já aprendi um pouquinho. Então quando não sei alguma coisa ou não entendo, entro no Google [...]. (Fac.3.3)

[...] sei entrar no Google tradutor pois na internet aparece vários nomes e as vezes em inglês. (Fac.3.4) 
Os discursos apresentados abaixo evidenciam a habilidade desenvolvida para manusear o mouse, a capacidade de modificar o fundo de tela e aumentar o tamanho da fonte no texto que será lido, demonstrando assim, destreza na interação com a máquina e a superação de eventuais dificuldades de ordem física ou cognitiva, impostas pelo processo de envelhecimento físico.

[...] não tenho dificuldades de mexer no mouse [...]. (Fac. 5.4)

[...] sei colar fundo de tela [...]. (Fac. 5.5)

[...] quando eu abro um site e tenho dificuldades com o tamanho da letra eu vou lá e aumento [...]. (Fac.5.6)

[...] escolher o tamanho da letra, da folha que vai imprimir, no cantinho e baixo e está escrito diminuir e aumentar a letra eu vou lá e faço, ponho $100 \%$ e vou aumentando é bem fácil [...]. (Fac.5.7)

\section{Subcategoria 1: Usando programas e dispositivos}

A facilidade para abrir e fechar programas e dispositivos pode ser observada nos discursos a seguir, evidenciando que uma vez aprendida ou desenvolvida a nova habilidade, essas são plenamente incorporadas aos saberes e habilidades já sedimentados, embora os idosos possam ter mais dificuldades ou ser mais lentos para aprender coisas novas ou desenvolver novas habilidades. Os relatos dos idosos encontram-se a seguir.

[...] todos os programas eu abro e fecho com segurança [...]. (Fac. 1.4)

[...] sei ligar e desligar o computador com facilidade, sei tirar o pen-drive, e faço legalzinho para não dar pane, não danificar o computador [...]. (Fac.1.6)

As facilidades são ligar e desligar o computador, aguardar abrir, certo que às vezes isso demora um pouco. [...]. (Fac. 2.4)

[...] no inicio eu precisava marcar em uma folha de papel minha senha que eu não conseguia gravar, não sabia como entrar no computador tinha que marcar tudo no papel, até que hoje faço rapidinho. (Fac.3.8)

\section{[...] entrar em jogos [...]. (Fac.5.2)}

\section{Subcategoria 2: Navegando na internet}

A subcategoria dois expressa a facilidade de alguns dos sujeitos para navegar na internet, e demonstram no nosso entender que os idosos se apoderaram desse conhecimento e fazem uso do mesmo para buscar textos para leitura e estudo, ler jornal, com o intuito de se manter atualizados e fazer compras.

Consigo procurar textos [...]. (Fac.3.7)
As facilidades foram muitas, bastante, ler jornal, [...] estudo, se quero saber alguma coisa eu vou direto e leio [...]. (Fac. 1.2)

\section{[...] pesquisa de compras [...]. (Fac.1.3)}

\section{B. Dificuldades no uso do computador ou internet}

A partir dos discursos dos idosos foi possível identificar três categorias que representam as dificuldades encontradas por eles no uso do computador ou internet.

\section{Categoria 1: Limitação física ou cognitiva}

A idade avançada, a lentidão no processamento das informações e a diminuição na capacidade de retê-las, se apresentam como um dificultador da aprendizagem, suscitando um empenho maior e mais tempo de treinamento para acessar a internet e as redes sociais. Esses momentos podem ser observados nas falas descritas a seguir.

A dificuldade está mais mental, no caso a gente já está com certa idade então fica mais difícil. (Dif.2.1)

[...] tem coisa que no caso você tem que treinar várias vezes [...]. (Dif.2.2)

[...] as maiores dificuldades que tive foram as gravações dos nomes das redes sociais, porque não começa direto na internet, então tinha dificuldade de gravar aqueles nomes e sites que tinha que entrar [...]. (Dif.3.2)

\section{Categoria 2: Ausência de instrutor}

Na categoria dois emergiu como dificuldade, a falta de um instrutor para orientar e auxiliar nos problemas de manuseio da máquina, no uso das ferramentas digitais para fazer pesquisas. Esse momento pode ser observado nos relatos abaixo.

\section{[...] pois se eu não sei não vou mexer. (Dif.1.1)}

[...] às vezes eu tinha acesso ao computador, mas não tinha uma pessoa para me ensinar [...]. (Dif.3.1)

No momento estamos sem o professor que ficava nos orientando [...] agora ficamos a maior parte do tempo só [...]. (Dif.3.3)

[...] então fico parado, pois não sei o que fazer e vou perguntar para quem, não tem ninguém para ensinar. (Dif.3.13)

[...] a maior dificuldade é a falta de pessoas para nos auxiliar na hora de mexer [...]. (Dif.4.1)

[...] falta de acompanhamento [...]. (Dif.4.3)

[...] sinto falta de alguém que me ajude desenvolver melhor minhas pesquisas, aqui há falta de monitores. (Dif.4.5) 
Categoria 3: Falta de conhecimento para interagir com a máquina e usar ferramentas digitais

A falta de conhecimento para interagir com a máquina, usar programas ou navegar na internet é um impeditivo para a acessibilidade.

Os relatos a seguir exemplificam os problemas e dificuldades:

No inicio minha maior dificuldade era mexer com mouse, clicar com o dedo direito e esquerdo, aquela setinha, eu não tinha habilidade de mexer com a mão, tipo mexer no botão, apertar e clicar, não conseguia ver a flecha quando mexia no mouse com a mão [...]. (Dif.3.4)

[...] tem programas que não sei mexer, como por exemplo, fazer uma planilha [...]. (Dif.3.5)

[...] hoje só consigo um pouco fazer convites, foi o que aprendi, o instrutor me ensinou [...]. (Dif.3.6)

[...] ele ensinou outras coisas, mas não consigo desenvolver sozinho, tipo fazer umas coisas mais coloridas, uma árvore de natal, mas só não consigo fazer sozinho [...]. (Dif.3.7)

Não sei [...] copiar e colar, é isso que preciso aprender. (Dif.3.14)

Eu tenho e-mail no Yahoo, mas não sei como entrar em outros e-mails como Gmail, Terra [...]. (Dif.3.10)

[...] eu preciso desenvolver a pesquisa e tenho dificuldade, se eu não souber não vou pra frente com a pesquisa [...]. (Dif.1.2)

A maior dificuldade é quando estou no computador e não sei o que fazer para seguir com a pesquisa [...]. (Dif.3.12)

Tenho dificuldades de manipular o equipamento [...]. (Dif.4.2)

[...] os computadores aqui sempre têm vírus e não sei como fazer [...]. (Dif.4.4)

Enviar um link para outros, baixar e arquivar documentos da internet, publicar no mural e se comunicar de forma síncrona no Facebook, são dificuldades citadas neste estudo.

[...] mandar um link já fica mais complicado, é o que eu estou começando a aprender agora[...]. (Dif.2.3)

[...] não sei baixar da internet para arquivar no computador [...]. (Dif.3.8)

[...] colar no Facebook eu preciso ainda aprender também mandar para outra pessoa [...]. (Dif.3.9)

[...] eu entro no Facebook, mas não sei como mandar mensagens em particular às vezes quero mandar uma mensagem para uma pessoa que não interessa as outras como mandar mensagens de natal para meus filhos, é isso que quero aprender mandar apenas para a pessoa específica e não para todos [...]. (Dif.3.11)

\section{DISCUSSÃO}

Realizar pesquisas em instituição que visa o cuidado e a promoção social de idosos em situação de rua ou vulnerabilidades social é muito importante para a determinação de políticas públicas e das atividades oferecidas a essa população, que englobam a questão da inclusão digital que permite o resgate da dignidade, da autoestima, de relacionamentos familiares distantes e empodera o indivíduo.

Com relação às facilidades no uso do computador ou internet, consideramos que a inclusão digital traz como benefícios aos idosos, tanto na dimensão individual quanto na social, a manutenção da memória, a superação de dificuldades cognitivas e o resgate ao sentido de pertença à sociedade contemporânea.

Corroborando essa visão, estudos ${ }^{(5,8-10)}$ citam como benefícios do uso das tecnologias da informação e comunicação pelos idosos, o resgate da autoestima, a aproximação com familiares e amigos distantes e o restabelecimento de relações sociais contemporâneas, a superação de dificuldades físicas, a melhora no desempenho cognitivo e consequente resgate da dignidade.

Com relação às facilidades de esclarecer dúvidas é condição facilitadora no processo de aprendizagem do uso do computador e acesso à internet o auxílio dos monitores e a interação com os pares se ajudando mutuamente ${ }^{(11-13)}$

A possibilidade de consultar um manual com orientações gerais para usar o computador e a internet também emergiu na fala de um dos participantes do estudo. Esse manual de orientações seria uma opção na ausência de um instrutor.

Resultado semelhante aparece em estudo ${ }^{(11)}$ com idosos que teve como objetivo identificar condições facilitadoras e limitadoras no uso do computador nas aulas de informática, em uma Universidade Aberta à Terceira Idade. Os idosos sugeriram como condição facilitadora, a criação de manual com instruções básicas que possibilitem suplantar as barreiras para operar o computador na ausência do instrutor.

A importância da curiosidade é ressaltada como um dos motivos que induz o idoso a se interessar pelo uso da internet e suas ferramentas; essa mesma curiosidade aumenta a capacidade de aprender informática e de encontrar possibilidades de uso de cada uma das ferramentas computacionais ${ }^{(14)}$.

Em estudo ${ }^{(5)}$ exploratório com 55 idosos que frequentavam um Telecentro na Cidade de São Paulo, os autores identificaram uma pequena parcela $(5,5 \%)$ que referiu ter aprendido a usar o computador no trabalho e 3,6\% que aprenderam a usar o computador sozinho.

As aptidões desenvolvidas ao longo da vida, como a datilografia e o contato anterior com equipamentos eletrônicos, se apresentam como condição facilitadora para os idosos no processo de aprendizagem da informática ${ }^{(11)}$. 
A competência no uso do correio eletrônico para receber ou enviar mensagens, participar de pesquisas, frequentar as redes sociais de relacionamento pessoal para se comunicar com parentes, amigos, e usar ferramentas de busca para esclarecer dúvidas apareceram nos discursos de alguns dos sujeitos. Essas habilidades demonstram a apreensão do conhecimento sobre o uso das ferramentas da internet e a inserção dos idosos no mundo digital através da comunicação, que consideramos a forma mais elementar de se fazer presente em um determinado espaço, seja ele real ou virtual.

Para a maioria das pessoas, mandar uma mensagem pelo correio eletrônico é apenas um momento de comunicação, mas para o idoso, receber uma mensagem eletrônica tem um valor diferente; é o momento em que ele se sente lembrado por outros ${ }^{(14)}$.

Um estudo(12) afirma que é o interesse que impulsiona a apreensão do conhecimento e, ainda, que o grande interesse do idoso que busca um curso de informática é a internet, para desenvolver pesquisas e consultas, mas muito mais do que isso, eles anseiam a comunicação através do correio eletrônico e do MSN ${ }^{\circledast}$.

O uso de buscadores em pesquisas, do correio eletrônico, dos comunicadores instantâneos como o $\mathrm{MSN}^{\circledast}$ e das redes sociais de relacionamento pessoal para manter contato com familiares e amigos, ou mesmo fazer novas amizades, foi identificado em estudos ${ }^{(5,10)}$ com idosos que frequentavam cursos de informática.

Destaca-se que o grau de escolaridade do idoso interfere na capacidade de compreensão de uma palavra ou texto, principalmente palavras mais eruditas ou termos estrangeiros incorporados ao vocabulário corrente, principalmente os ligados ao uso do computador ou internet. Em um estudo ${ }^{(12)}$ descritivo etnográfico baseado em observação participante, os autores identificaram que dentre os participantes de uma oficina de inclusão digital, grande parte dos alunos apresenta dificuldade na compreensão de termos estrangeiros, no entanto, essa dificuldade é contornada com o uso do Google ${ }^{\circledast}$ para buscar o significado do vocábulo.

A maior parte dos idosos inicia o curso de informática sem ao menos ter noção de como ligar o computador e, após dois meses, sentem-se orgulhosos de conseguir ligar o computador, navegar na internet e utilizar as ferramentas digitais ${ }^{(12)}$.

Para dominar o computador e o uso das ferramentas da internet é preciso treinamento, fato ressaltado em estudos ${ }^{(11-12)}$ onde os participantes da pesquisa referiram o treinamento em casa como condição favorecedora do processo de aprendizagem.

Usar o computador com a finalidade de estudar, ler jornal, se manter atualizado e fazer compras é relatado em dois estudos $^{(5,10)}$. Esse comportamento de busca de informações por meio da leitura, e principalmente do uso das ferramentas computacionais, se apresenta como exercício de estimulação da memória e da capacidade de assimilação de novos conhecimentos.

As dificuldades no uso do computador ou internet estão relacionadas a eventos de ordem física ou cognitiva que dificultam a interação do idoso com a máquina. Esses eventos dizem respeito à diminuição da capacidade para memorizar e resgatar as informações que permitem ligar o computador e acessar a internet, assim como a hipoacusia, a diminuição da acuidade visual e os problemas articulares são ocorrências de ordem física relatados pelos idosos ${ }^{(13)}$.

Ressaltamos que os eventos de ordem física ou cognitiva são dificultadores e não impeditivos do processo de aprendizagem dos idosos.

Estudos $^{(11-12)}$ afirmam que grande parte dos idosos que frequentam cursos de informática não tem nenhuma vivência anterior com o computador, sendo este fato gerador de diversos temores, como, por exemplo, quebrar o equipamento por não saber como usá-lo de forma correta, tornando necessário, portanto, a presença de um monitor.

$\mathrm{Na}$ Categoria 3: Falta de conhecimento para interagir com a máquina e usar ferramentas digitais, emergiram dificuldades relacionadas à falta de habilidade para trabalhar com os botões do mouse, perceber o indicador do cursor, executar procedimentos tecnicamente rotineiros como copiar e colar, acessar ferramentas como o e-mail, avançar em uma pesquisa ou mesmo, procedimentos mais complexos, como fazer planilhas, desenvolver trabalhos gráficos e escanear a máquina para eliminar vírus.

$\mathrm{Na}$ interação do idoso com o computador, os erros estão presentes, e a maioria deles acontece em função da pouca intimidade com o equipamento, principalmente com a sensibilidade do mouse durante seu manuseio e a localização da seta para posicionar o cursor, caracterizando-se assim como um dificultador do aprendizado ${ }^{(12-13)}$.

A disposição dos ícones que possibilitam abrir, baixar, salvar, anexar ou enviar anexos, e ainda ter a certeza de que a mensagem foi enviada com sucesso foi identificada como dificultador na interação com as ferramentas digitais ${ }^{(14)}$.

\section{CONCLUSÃO}

Apesar de composto por cinco sujeitos participantes, entendemos que o objetivo do estudo foi atingido, pois emergiram dos discursos as facilidades e dificuldades dos idosos em situação de rua ou vulnerabilidade social, no uso do computador ou internet. Os resultados vão ao encontro do descrito em estudos nacionais desenvolvidos com idosos não caracterizados como em situação de rua ou vulnerabilidade social e podem contribuir em pesquisas futuras.

A metodologia se mostrou adequada ao objetivo do estudo. Assim, emergiram como facilidades a presença de monitores, que colaboravam e esclareciam as dúvidas propiciando o aprendizado e favorecendo a inclusão digital. Também foi exposto que a possibilidade de consultar um manual com orientações gerais para usar o computador e a internet seria uma opção na ausência de um instrutor.

Em relação à interação com a máquina e a usar ferramentas digitais, ficou evidente que, quando o idoso é estimulado, ocorre um enriquecimento em sua aprendizagem e que a curiosidade e a proatividade facilitam o caminho para a inclusão digital.

A competência no uso do correio eletrônico, no manuseio ferramentas de busca e frequência nas redes sociais de 
relacionamento pessoal, demonstrou a apreensão do conhecimento sobre as ferramentas da internet e a inserção dos idosos no mundo digital por meio da comunicação, bem como a representação de que esse momento tem um valor diferente para o idoso, em que ele se sente lembrado por outros.

Quanto às dificuldades, foi relatado que a lentidão no processamento das informações e a diminuição na capacidade de retê-las suscitaram um empenho maior e mais tempo de treinamento para acessar a internet e as redes sociais, fatos que não foram impeditivos do processo de aprendizagem dos idosos. Emergiu ainda como dificuldade e impeditivo para a acessibilidade, a falta de um instrutor para orientar e auxiliar nos problemas de manuseio da máquina, no uso das ferramentas digitais para fazer pesquisas, a falta de conhecimento para interagir com a máquina e usar programas ou navegar na internet.
Como contribuições, este estudo reafirma a lacuna existente em relação às pesquisas desenvolvidas por enfermeiros, voltadas para essa parcela da população idosa. Os estudos podem contribuir com evidências que direcionem a formulação de políticas públicas voltadas para os idosos em situação de rua ou vulnerabilidade social e a inserção do enfermeiro nos espaços de promoção social.

Sugerimos novos estudos sobre o contexto em que vivem os idosos em situação de rua ou de vulnerabilidade social e sua inclusão digital, pois contribuirão com propostas de intervenção por parte de profissionais de diversas áreas como os educadores, profissionais da saúde especialmente o enfermeiro, e assistência social. Desta forma a participação de Organizações não Governamentais e de instituições de assistência social pode tirar o idoso da situação de rua ou vulnerabilidade social e inseri-lo na sociedade, devolvendo assim sua dignidade e autoestima.

\section{REFERÊNCIAS}

1. Pereira CP. Rua sem saída: um estudo sobre a relação entre o Estado e a população de rua de Brasília [dissertação]. Brasília (DF): Universidade de Brasília; 2008.

2. Brêtas ACP, Marcolan JF, Rosa AS, Fernandes FSL, Raizer MV. Quem mandou ficar velho e morar na rua? Rev Esc Enferm USP [Internet]. 2010 [acesso em 12 de julho de 2012];44(2):476-81. Disponível em: http://www.scielo. br/pdf/reeusp/v44n2/33.pdf

3. Gutierrez BAO, Silva HS, Rodrigues PHS, Andrade TB. Reflexões bioéticas sobre o processo de envelhecimento e o idoso morador de rua. Estud Interdiscip Envelhec [Internet]. 2009 [acesso em 31 de maio de 2012];14(2):187205. Disponível em: http://seer.ufrgs.br/RevEnvelhecer/ article/view/7537

4. Rocha FCV, Brito CMS, Luz MHBA, Figueiredo MLF. Análise da produção científica sobre o idoso na REBEn. Rev Bras Enferm [internet]. 2007 [acesso em 27 de junho de 2014];60(4):449-51. Disponível em: http://www.scielo. br/pdf/reben/v60n4/a17.pdf

5. Frias MAE, Peres HHC, Paranhos WY, Leite MMJ, Prado $C$, Kurcgant $\mathrm{P}$, et al. Utilização de ferramentas computacionais por idosos de um Centro de Referência e Cidadania do Idoso. Rev Esc Enferm USP [Internet]. 2011 [acesso em 12 de julho de 2012];45(nº. Esp.):1606-12. Disponível em: http://www.scielo.br/pdf/reeusp/v45nspe/ v45nspea11.pdf

6. Gil AC. Como elaborar projetos de pesquisa. 5. ed. São Paulo (SP): Atlas; 2010.

7. Bardin L. Análise de conteúdo. São Paulo (SP): Edições 70; 2011.

8. Sales MB, Guarezi RC, Fialho FAP. Infocentro para a terceira idade: relato de experiência de aprendizagem por pares. Rev Digital CVA Ricesu [Internet]. 2007 [acesso em 29 de outubro de 2010];4(13):[cerca de 22 p.]. Disponível em: http://pead.ucpel.tche.br/revistas/index.php/ colabora/article/viewFile/88/76

9. Shrapira N, Barak A, Gal I. Promoting older adults' well-being through internet training and use. Aging Mental Health. 2007; 11(5):477-84.

10. Vieira MC, Santarosa LMC. O uso do computador e da internet e a participação em cursos de informática por idosos: meios digitais, finalidades sociais. In: Anais do $20^{\circ}$ Simpósio Brasileiro de Informática na Educação; 2009 nov. 17-20; Florianópolis, Brasil. Florianópolis (SC): UFSC; 2010.

11. Sá MAAS, Almeida LR. Idosos e Computadores: facilitadores e limitadores no processo de aprender. In: III Congresso Ibero-americano de Psicogerontologia; 2009 nov. 3-5; São Paulo, Brasil. São Paulo (SP): PUC-SP; 2009.

12. Tezza R, Bonia AC. O idoso e a internet: uma etnografia sobre interação e aprendizagem. Perspectivas Ciências Computação [Internet]. 2010 [acesso em 31 de maio de 2012 mai 31];15(1):185-97. Disponível em: http:// portaldeperiodicos.eci.ufmg.br/index.php/pci/article/ view/825/709

13. Silveira MM, Kümpel DA, Rocha JP, Pasqualotti A, Colussi EL. Processo de aprendizagem e inclusão digital na terceira idade. Rev Tecnologia Sociedade [Internet]. 2011 [acesso em 31 de maio de 2012];13. Disponível em: http://200.134.25.85/revistas/tecsoc/revista 13.html\#a8

14. Machado LR, Souza VBA. Um estudo sobre o uso da internet por idosos. In: International Association for Development of the Information Society, organizador. Conferência IADIS Ibero-Americana: www/internet 2006; Oct 6-7; Murcia, Espanha. Murcia: IADIS; 2006. p. 401-4. Disponível em: http://www.poliguarda.ipg.pt/evento.asp?evento $=3$ 